\title{
Evaluation Study of Women in Information and Communication Technology from Feminist Perspective
}

\author{
Dr. Kanchana Goudar, Principal, Lorven educational Centre, Bangalore, India. \\ Mrs. Shilpa shree.R.L. H.O.D of Lorven educational centre, Bangalore, India.
} Mr. Mohana.C Asst. Prof of Lorven educational center, Bangalore, India.

\begin{abstract}
Women managers working in IT sector counts very low compared to male. The non existence of data on female managers in India reflects low participation of female in ICT. Recent studies for every hundred men only two women will gain administrative and managerial positions in India. Although various facilities are provided to growing women population at IT still women managers roles are not reaching IT market. Several hurdles like Gender stereotypes and attitudes, family responsibilities, working hours, health constraints are the key factors where women managers decline. Each key factor as different individual views and gives different clarity. Evolution and evidence obtained from personal interviews considering 50 female delegates enrolled as IT specialist and 10 female managers from different companies for clear information follow structural questionnaire to elect and record the data.
\end{abstract}

Keywords: Communication technology, Feminist, Organization development, Strategic market,

\section{INTRODUCTION}

With growing ICT and IT, there is big demand of women managers in today's global economy. The lack of female IT specialist is a result due to some gender dominance in the field. In other words ratio of female to males in targeted positions is imbalance. According to Truth (2004), addresses this issue and measures to overcome it. Other challenges include policy making and strategic work place. Human resource aimed at wooing and maintaining feminine gender in this profession. The present study concerns this inequality existence and discussed ways to overcome this gap. It also focuses in broader aspect that both developed and developing countries. Exact information of women managers at higher position obtained is very minimal. The ways in which these problems can be alleviated are also explored.

Institutional, individuals, sociological traits have greatly influence the managers in which various challenges women face as per observation. The study highlights the socialization process and individual perspective of women managers.

Adya et al(2006) classifies indicators into social factors(family and peers) and individual differences. This paper concerns various issues related to employment posts, duties, activities experience and roles responsibilities. The selection of profession as well as decision making responsibilities are held by men. The paper discusses whether women lead better than men differently. It also addresses career choice patterns, mobility constraints, girls and women Independence.

As such the paper will try to answer the following questions.

1. Does social influence including gender stereotypes, role models, peers, family have any impact on career choice of ICT women.

2. Does professional factors including teachers/ counselors, schools and personal technicians, technical resources and identical sex education have any impact on career choice.

3. what is the manifestation of social and private sectors as per various ethnic cultures?

4. What are the impact of individual differences to one's choice of IT profession with respect to problems in developed and underdeveloped countries are undergoing

5. What are influences of social and individual differences towards decision making of IT professional?

Determinants:

1.Over generalizations: thinking patterns needs and communication styles of women's are over Biased. myths and stereotypes of men and social process are still over taken at IT sectors.

2. gender politics:- Psychological feelings that women given more power become more dominant than men. In order to demotivates and deprives them financial stability 
3.gender sensitivity: policies and norms only theoretical but not implemented practically. professionals are not concerning it. As per observations men over dominance in Science, Engineering and Technology related discipline where ever computers act as a possession to them this show how socialization acts Adversely to feminine gender.

4.Level of literacy and education: As per Census $2 / 3^{\text {rd }}$ of Indian population constitutes women illiteracy $\mathrm{s}$ a result male orientation of computer usage increases access to technology for female decline gradually.

5.social and cultural norms: Female find PIC very insane To us as a result of excuses of IT declines. male stereotypes that female responsibilities lies within family boundaries economic and time concern constraint deprive usage of IT to women.

6.Skill: women as leader can leverage their natural inclination towards transformational qualities. so female managers need to show strength and sensitivity in terms of Talent by setting up high expectation.

7. learning approaches and genders: Birthmark of women Where she is In calculated with concentrate learning system styles traditional form of raising a girl child leads to improper female managers.

\section{Questionnaire}

1.What are the gender obstacles experienced being on women managers in IT sector?
A. Gender biased
B..higher opportunities
C.salary D.others

a. 22

b. 10

c. 11

d.07

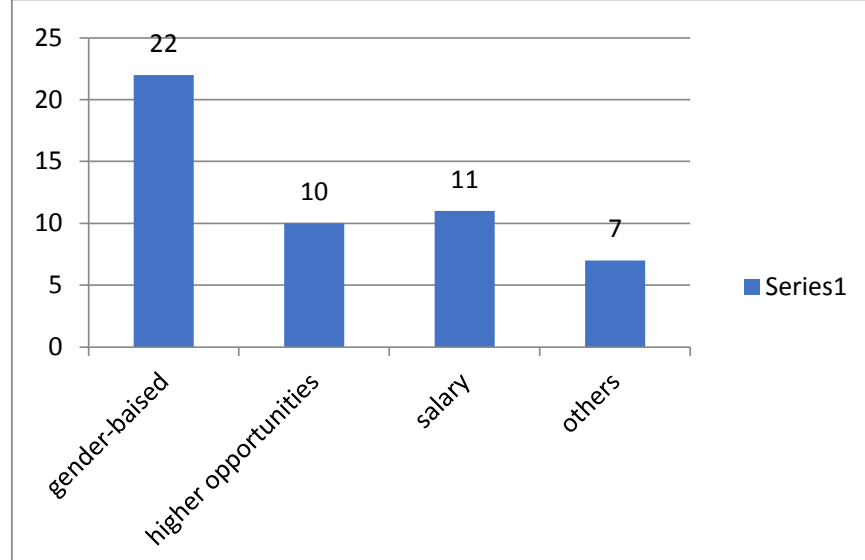

\section{Graph.1 gender obstacles in IT sector.}

2. What is the best tool to asses' gender imbalance in IT sector?
a.Physical representation
b. Psychological dominance
c. professional view
d.morality

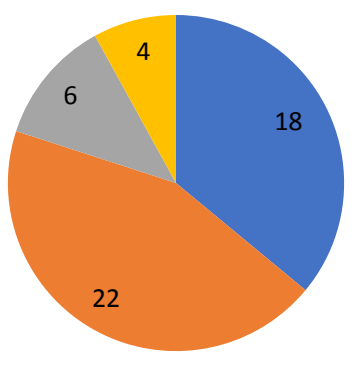
- Physical representation
- Psychological dominance
professional view
morality

\section{Graph 2. Best tool to assess gender imbalance}

3. Does women are not efficient for higher positions in IT?
A.Not Efficient
B.Partial
C.Yes
Efficient
D.None Of The Above

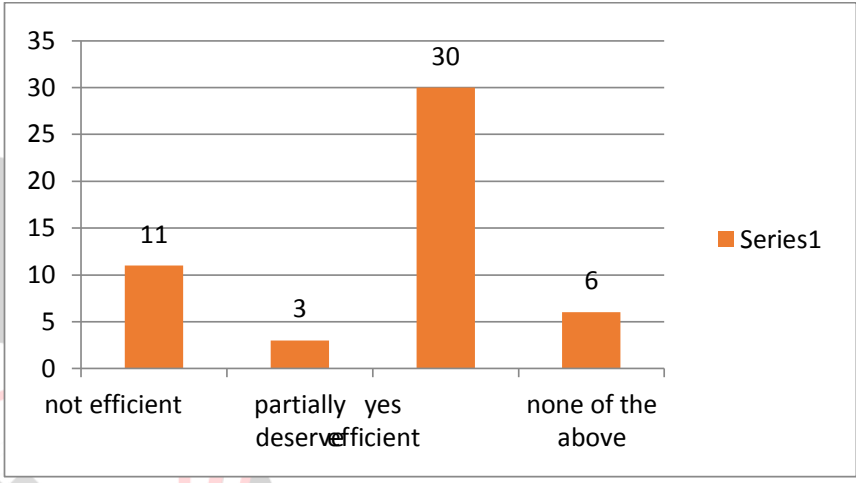

\section{Graph 3 higher positions in IT}

4.What are the several opportunities for women managers can feel comfortable in their positions

A.Mobility B.Leave Facility C. Work From Home D.Comfortable Support Than Others Feel

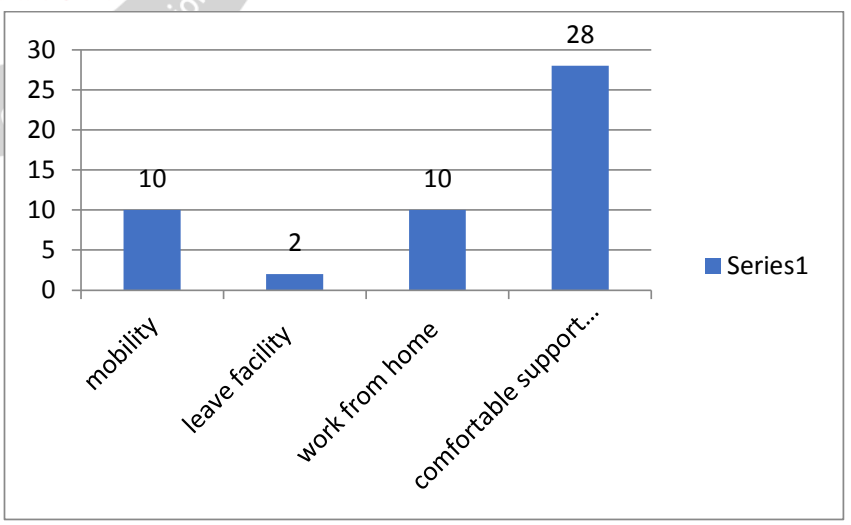

\section{Graph 4. Women comfortable in their positions}

5.Do really women are not fit for higher position in IT sector?
A.No
B.Highly Fit
C.Never
D.Not Sure 


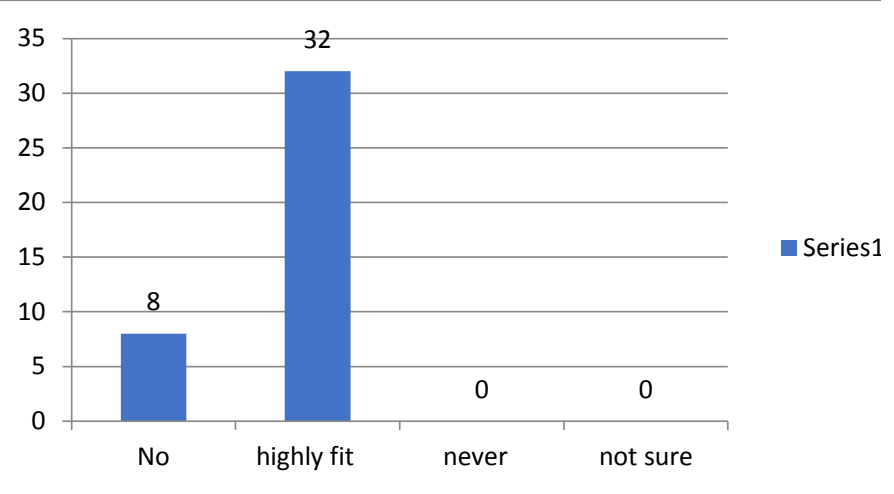

Graph 5. Not-fit for higher position in IT sector

\section{RESEARCH FINDINGS}

1.gender obstacles through gender biased is maximum for women at IT

2..asses of gender imbalance in IT sector through Psychological dominance is prominent

3.women are more efficient than men for higher positions if training in managerial skills are given

4.mobility and work from home are equally chances to women to select jobs at IT

5.women really fit for higher administrative and managerial positions without hindrance

\section{SOLUTION TO CHALLENGES}

1.change of attitude: right person to right job irrespective of sex, age, marital status recruitment of women at all levels of organization. decision making authorities within her hand.

2.Increasing number of female role models: few are less number of women's entrepreneurs industrialize, IT specialist recovered to lack of data senior female managers.

3. Training increased specialist access :junior specialist or managers provided with training programs workshops as well as projects.

4. Increased pay :certain job opportunities based on pay scale specific to females provide more incentives at least two additional financial gain to family.

\section{RECOMMENDATION}

1.The negative projection and degrading images of women at IT through communicational media must be changed the violent and pornographic media Clippings of women and their participation have adverse effect on society .

2.women should to be empowered by answering their skills, knowledge and access to IT. This will strengthen their ability to to combat negative portrays of women's leadership traits.
3. gender biased programming should be abolished the self regulatory mechanism and approaches.

4. women need to be involved in decision making regarding development of new technologies in order to participate completely in their growth and impact.

5. there is no "one size fits all" design for ICT network. So women community in social, economic and political organizations information needs vary. Therefore design and implementation of project should be driven by specific to needs of women.

\section{Questionnaire}

1. what are the gender obstacles experienced being on women managers in IT sector?

a.gender biased b.higher opportunities c.salary d.others
a. 22
b. 10
c. 11
d.07

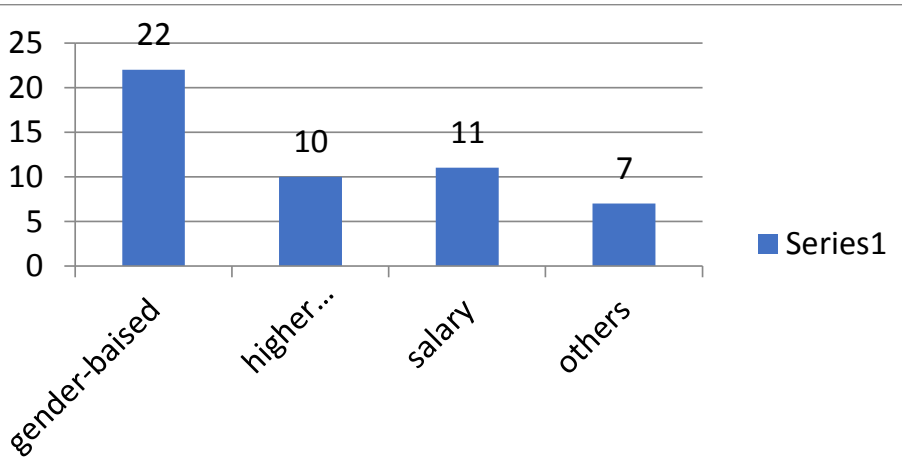

Graph.1 gender obstacles in IT sector.

2.What are the best tool to asses gender imbalance in IT sector?

a. Physical representation

b. Psychological dominance

c. professional view

d.morality

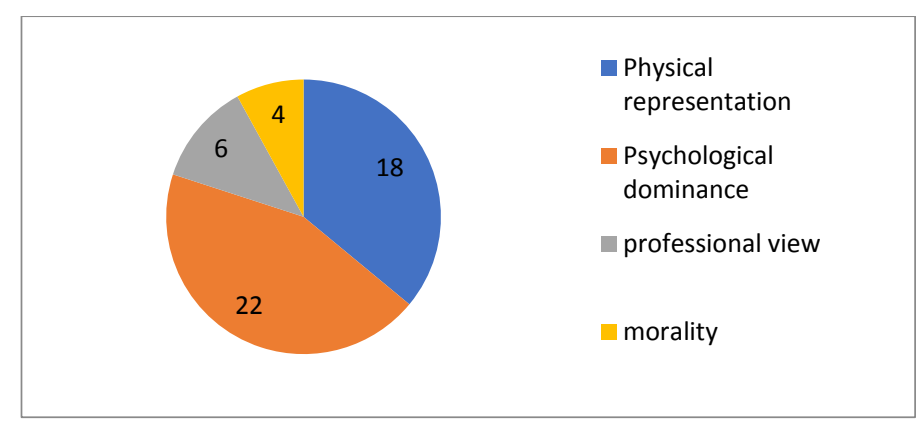

Graph 2. Best tool to assess gender imbalance

3.Does women are not efficient for higher positions in IT?

a.not efficient b.partial c.yes efficient

d.none of the above 


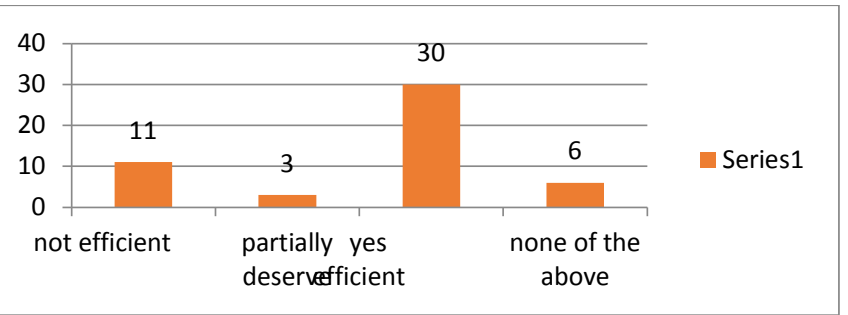

\section{Graph 3 higher positions in IT}

4.what are the several opportunities for women managers can feel comfortable in their positions

a.mobility b.leave facility c. work from home d.comfortable support than others feel

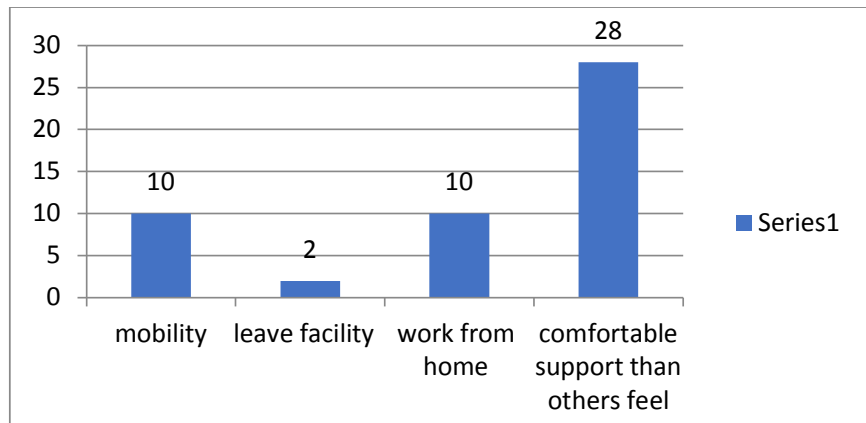

Graph 4. Women comfortable in their positions

5.Do really women are not fit for higher position in IT sector?

a.No b.highly fit

d.not sure

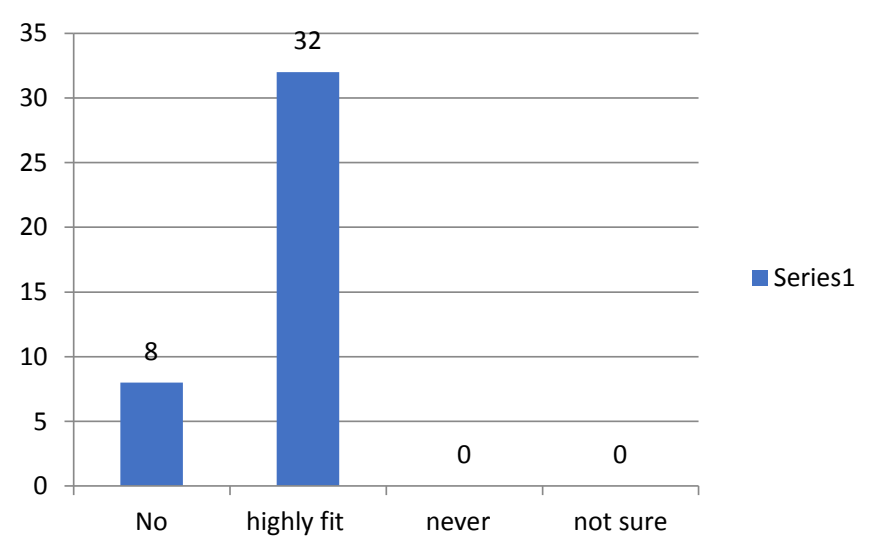

\section{Graph 5. Not-fit for higher position in IT sector}

\section{Research Findings}

1.gender obstacles through gender biased is maximum for women at IT

2..asses of gender imbalance in IT sector through Psychological dominance is prominent

3.women are more efficient than men for higher positions if training in managerial skills are given

4.mobility and work from home are equally chances to women to select jobs at IT 5.women really fit for higher administrative and managerial positions without hindrance

\section{CONCLUSION}

Today, IT is going as Express train at tremendous speed so proper utilization of ICT and IT tools needs to be implemented .The use of ICT helps to Bridge gap between women's opportunities for self employment in the informal and formal economy and higher growth sectors of the world's economy. In Formal sector all women needs to be empowered with more leadership skills to enrich her skill/talent at all levels of Management.

From the observation it is clear that there are several factors that affect the gender equity in the IT sector. Since factors are interrelated to one other therefore affect women career at IT

Though complete eradication of women equity cannot be achieved but can be reduced by considering countermeasures. Therefore gradually upgrade of women related policies and norms may be imposed in IT. Identifying key indicators and incorporating solutions to it at greatly influence significance is used to this study

\section{REFERENCES}

[1] Resanen,P.(2006).“Consumption disparities in information society.Comparing the traditional and digital decides in Finland ",International journal of sociology and social policy,vol.26,No.1/2,Pp.48-62.

[2] Trauth,M.E.(2002).“Odd girl out:an individual difference perspective on women in the IT profession", Information Technology \& People,Vol.15,No.2,Pp.98118.

[3] Liu, J.,Wilson, D.(2001)."Developing women in a digital world",Women in Management Review, Vol.16,No.8,Pp.405-416.

[4] Hanafi.A.,Wong, S.L.(2007).“Gender differences in Attitudes towards information technology among.

[5] Michie,S.,Nelson,L.D.(2006)."Barriers Women face in information technology careers. selfefficacy,passion and gender biases", Women in Management Review,Vol.21,No.1,Pp.10-27.

[6] Ladner,.J.S(2003) gender and information technology Professional ". SLA annual conference

[7] UNDP(2004),"'bridging the gender digital divide .A report on gender and ICT . 